\title{
Al1103 480550
}

U.S. DEPARTMENT OF COMMERCE

National Institute of Standards and Technology

NISTIR 4519

NIST

PUBLICATIONS

\section{Engineering Design Laboratory Guide}

\author{
Allison Barnard Feeney \\ Factory Automation Systems Division \\ National Institute of Standards and Technology \\ Gaithersburg, MD 20899
}

February 19, 1991

QC

100

.456

\#4519

1991

C. 2 

U.S. DEPARTMENT OF COMMERCE

National Institute of Standards and Technology

NISTIR 4519

\section{Engineering Design Laboratory Guide}

Allison Barnard Feeney

Factory Automation Systems Division National Institute of Standards and Technology Gaithersburg, MD 20899

U.S. DEPARTMENT OF COMMERCE

Robert A. Mosbacher, Secretary of Commerce

National Institute of

Standards and Technology

John W. Lyons, Director
February 19, 1991 



\section{Notes}

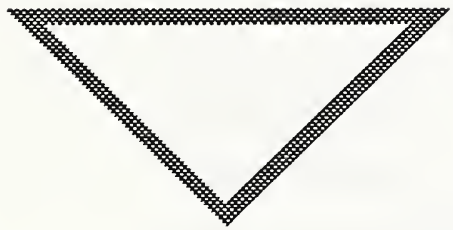

The author would like to acknowledge Peter F. Brown and Y. Tina Lee for their assistance in providing information necessary to complete this document.

This publication was prepared by United States Government Employees as part of their official duties and is, therefore, a work of the U. S. Government and not subject to copyright.

Certain commercial equipment, instruments, or materials are identified in this paper. Such identification does not imply recommendation or endorsement by the National Institute of Standards and Technology, nor does it imply that the materials or equipment identified are necessarily the best available for the purpose. 



\section{Table of Contents}

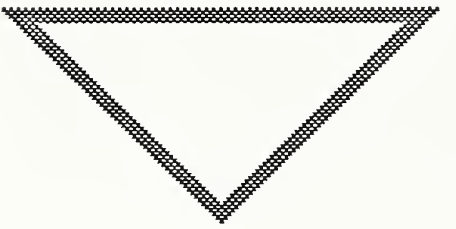

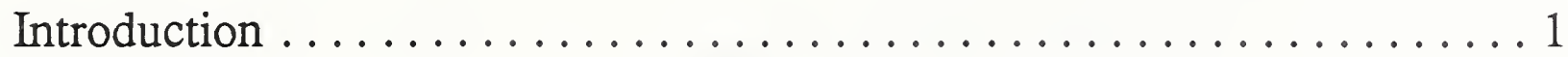

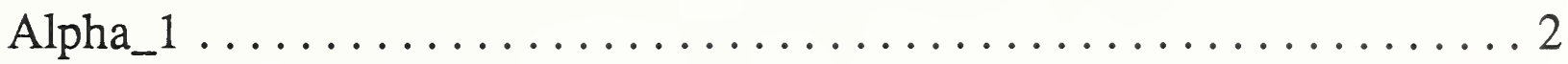

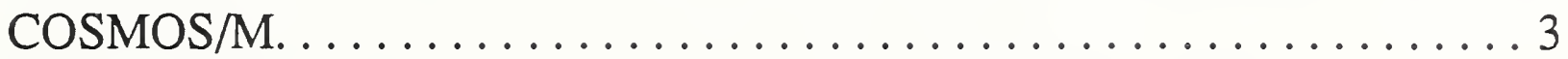

Design History Tool. . . . . . . . . . . . . . . . . . . . 4

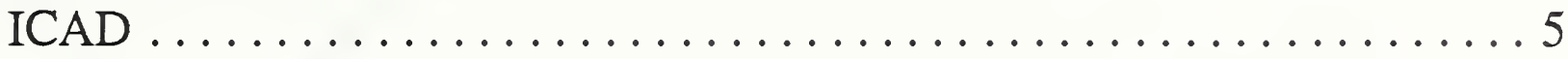

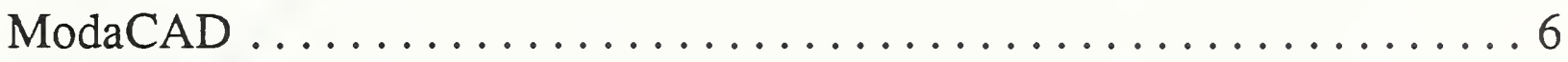

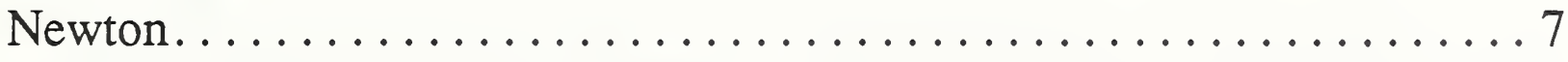

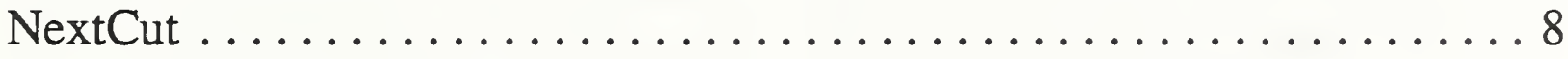

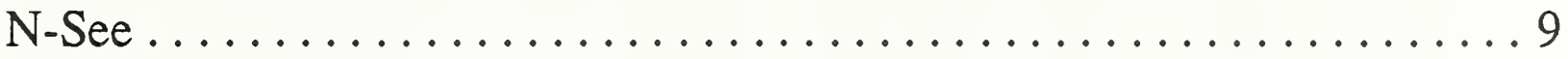

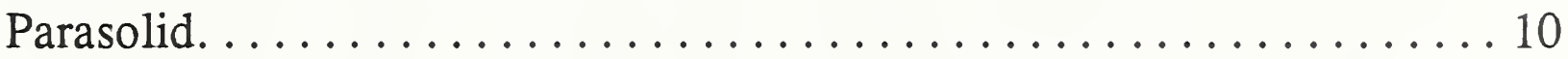

Supporting Hardware and Software .................. 11

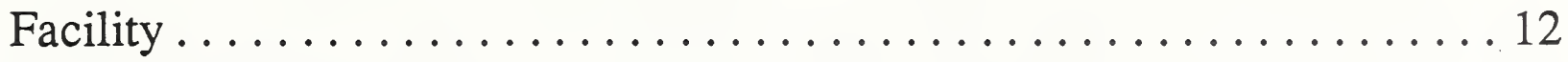

Research Opportunities ........................... 13 



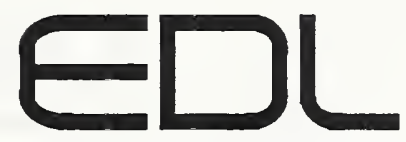

EngineeringDesignLab

\title{
Engineering Design Laboratory Guide
}

\author{
Allison Barnard Feeney \\ Factory Automation Systems Division \\ National Institute of Standards and Technology \\ Gaithersburg, MD 20899
}

\section{Introduction}

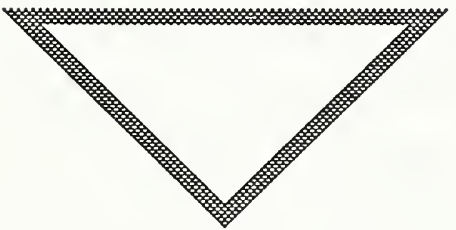

The Engineering Design Laboratory (EDL) was established by the Factory Automation Systems Division at the National Institute of Standards and Technology (NIST). The EDL was created to study the process of design, how design information can be represented, and how to make this information available to necessary systems throughout a product's life cycle. The EDL is a facility equipped with state of the art computers and software dedicated to these tasks.

The EDL supports projects funded by NIST, Defense Advanced Research Projects Agency (DARPA), Defense Logistics Agency (DLA), and the Navy. The goal of the EDL is to develop ways to represent design knowledge or intent in a manner that is compatible with the emerging standard for exchange of product model data, STEP. We are concentrating our efforts in the domain of rigid mechanical parts, including assemblies. A primary focus of the EDL has been working with DARPA to help build a community of researchers who are studying design representation.

One of the ways we are pursuing our goals is by making the EDL available to other researchers for collaborative or independent projects. NIST has a Research Associate Program through which a variety of arrangements between interested parties can be formalized.

The following pages contain descriptions of the equipment and software available in the EDL. This equipment and software is continually being upgraded and augmented to reflect the state of the art. 



\section{Alpha_1}

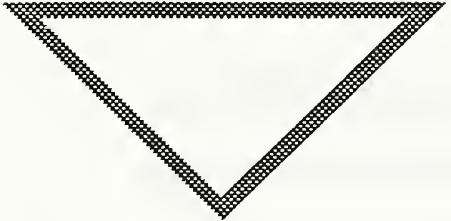

Alpha_1 is non-uniform rational bspline (NURB) based geometric modeling system developed at the University of Utah. It is available commercially through Engineering Geometry Systems. A goal of the Alpha_1 research has been to advance the integration of design, modeling, analysis and manufacturing to shorten and improve the quality of the overall process. Spline representations, used exclusively in Alpha_1, are necessary for a large class of objects including turbine blades, airplane fuselages, injection molded parts, and a great variety of common as well as unusual objects with difficult shapes. Alpha_1 models are described by a program or algorithmic procedures in a Lisp-like language. Changes to the master model are immediately reflected in the graphics window. Parametric part designs allow the user to develop new, high-level primitives to facilitate modeling designs with commonly used forms.

\section{Status:}

We will be working with the University of Utah to model a complex diesel engine in Alpha_1. In the EDL, Alpha_1 is currently only running on the Silicon Graphics Iris. With the next release of the software, we will be running Alpha_1 on the Sun 4 platform, only. In general, Alpha_1 runs on a variety of engineering workstations (Sun, HP, Silicon Graphics, Chromatics, Evans and Sutherland) and requires University of Utah's Portable Standard Lisp and X Windows or a native graphics system. Emacs is also needed for model editing via the command interface.

\section{Further Reading:}

Alpha 1 User's Manual, University of Utah, Salt Lake City, 1988.

\section{Developers:}

Elaine Cohen

Rich Riesenfeld

Department of Computer Science 3190 Merrill Engineering Building University of Utah Salt Lake City, Utah 84112

(801) 581-8224

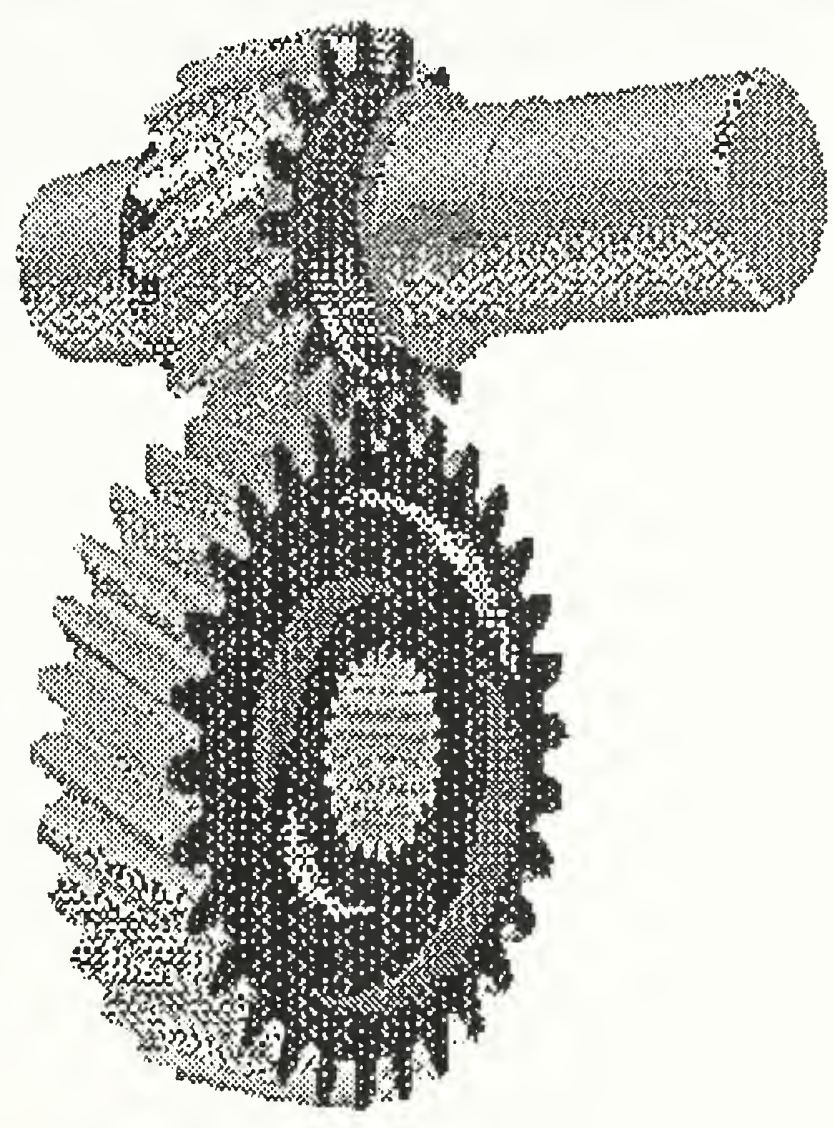

Worm gears modeled in Alpha_1. 



\section{COSMOS/M}

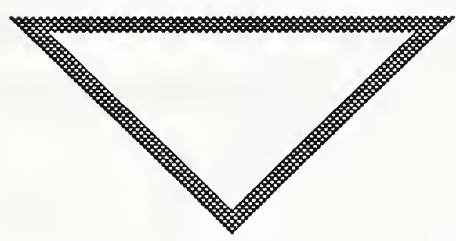

COSMOS/M is a commercially available finite element analysis package for general purpose structural analysis. COSMOS/M has a CAD-like front end mesh generator and an IGES interface to and from CAD systems. The capabilities installed at the EDL are: mesh generation, post processing, linear static and dynamic analysis, frequencies, mode shapes, dynamic responses, and heat transfer analysis.

\section{Status:}

We are using COSMOS/M for general structural analysis problems related to the Molecular Modeling Machine Project at NIST. We have Version 1.61 installed and running on the IBM PS/2 and on the Sun 4 workstation. COSMOS/M runs on a variety of PC platforms. It requires a graphics card and math co-processor. It also runs on several engineering workstations (e.g. Microvax, Sun, HP, Silicon Graphics, Apollo and ComputerVision).

\section{Further Reading:}

Lashkari, M., COSMOS/M User's Guide SRAC, Santa Monica, 1989.

Lashkari, M., GEOSTAR User's Guide, SRAC, Santa Monica, 1989.

\section{Developer:}

Structural Research and Analysis Corp.

1661 Lincoln Boulevard Suite 100

Santa Monica, California 90404

(213) $452-2158$ 



\section{Design History Tool}

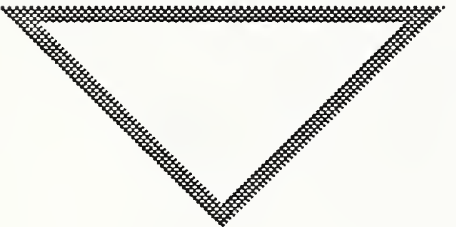

The Design History Tool is a research system from Oregon State University for representing design objects and the changes encountered as they evolve from abstract concepts to concrete forms. Design objects include assemblies, parts of assemblies and interfaces between assemblies and parts. All of the objects are described in terms of context sensitive form and function features. The changes that occur to the design objects are a result of design operators applied to the existing design information in the Mechanical Design Database. The representation of the changes the objects encounter provides a mechanism for capturing the relationship between constraints, design objects and the design process that describes the evolution of the objects from constraints.

\section{Status:}

We currently have the design of a battery housing modeled in the Design History Tool. The Design History Tool is running on the Sun 4 workstation in the EDL.

\section{Further Reading:}

Ullman, David G., Thomas G. Dietterich, Mechanical Design Process Research Group Research Overview, Oregon State University, Corvalis, Oregon, 1989.

Tikerpuu, Juri, David G. Ullman, General Feature-Based Frame Representation for Describing Mechanical Engineering Design Developed from Empirical Data, ASME CIE Conference, San Francisco, July 1988.

\section{Developers:}

David G. Ullman

Thomas G. Dietterich

Department of Mechanical Engineering

Oregon State University

Corvalis, Oregon 97331

(503) 737-2336 


\section{ICAD}

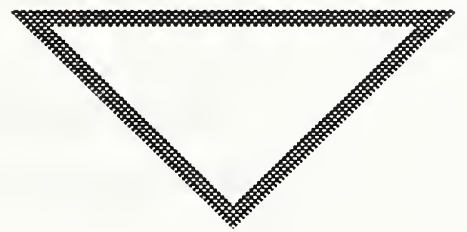

The ICAD System ${ }^{\mathrm{TM}}$ is an interactive, knowledge-based software product for mechanical design and manufacturing engineering automation. ICAD allows the user to build a model that describes the engineering, design, and manufacturing processes. Changes to input parameters cause a completely new design to be created automatically. ICAD attempts to capture the design intent behind the product design. The product model includes product structure and part dependencies, physical and geometric properties, manufacturing cost constraints, design specifications, decision criteria for material selection, standard parts from on-line catalogs, generation of manufacturing process plans, and access of information from external databases. From this model, the user can get a bill of material, completed detail designs, data for drawings, engineering reports, manufacturing process plans, numerical control programs, inputs to MRP systems and cost analyses.

Molecular Modeling Machine project at NIST. We have ICAD Version 2.1.2 for the Sun 4 workstation installed and running in the EDL. Other platforms supported by ICAD are the Apple MacIvory and Silicon Graphics.

\section{Further Reading:}

ICAD User's Manual, ICAD, Inc., Cambridge, Massachusetts, 1990.

ICAD Surface Designer TM User's Manual, ICAD, Inc., Cambridge, Massachusetts, 1990.

Wagner, Martin R., Understanding the ICAD System $\frac{\text { TM}}{}$, ICAD, Inc., Cambridge, Massachusetts, 1990.

\section{Developer:}

ICAD, Inc.

1000 Massachusetts Avenue

Cambridge, Massachusetts 02138

(617) $868-2800$

Rules are defined in ICAD Design Language $^{\mathrm{TM}}$ which is a declarative, object-oriented language. Geometry is defined with a complete set of geometric primitives. Geometry may also be input from a number of CAD systems.

\section{Status:}

ICAD and NIST are participating in a research agreement to develop representation schemes for Design Knowledge. This is being done in conjunction with part design for the
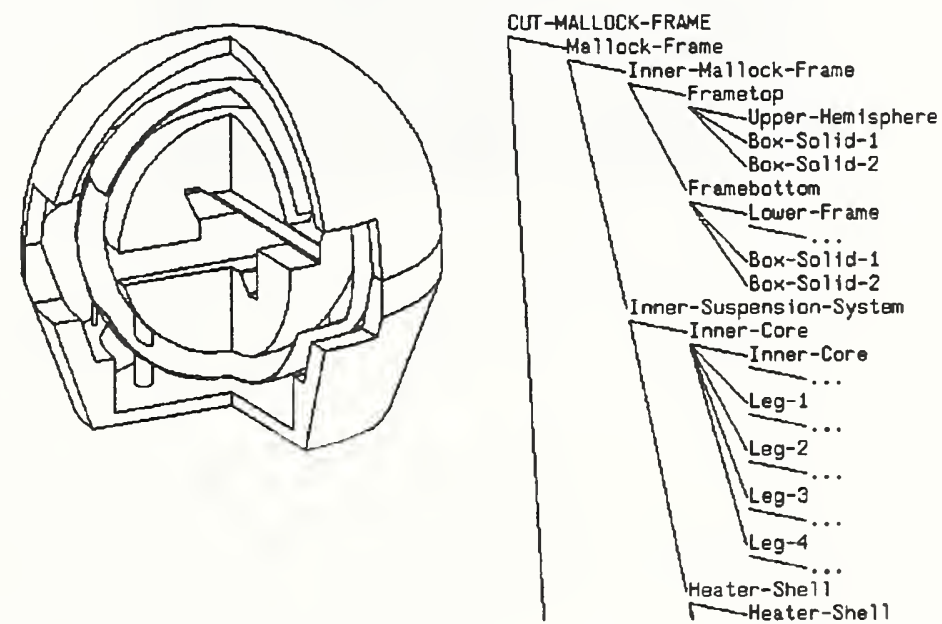

Molecular Modeling Machine part modeled in ICAD. 



\section{ModaCAD}

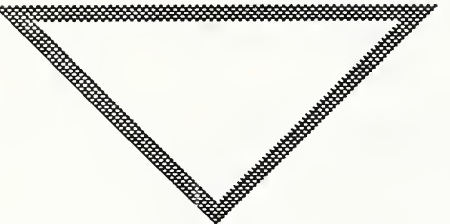

ModaCAD is an integrated system of application programs that addresses all aspects of apparel design and production. It is commercially available from ModaCAD, Inc., and runs on the Macintosh II series of computers. The ModaCAD programs installed at the EDL include a paint program, an image processing program, a program for designing fabric, a program for displaying fabric draped on a model (including lighting effects), a pattern design program (including grading), a program for generating pattern markers, a relational database program for apparel data, and a scheduling program to produce schedules for apparel manufacture.

\section{Status:}

The ModaCAD system is installed on the Macintosh IIx computer in the EDL. Included in the system configuration is an optical disk system containing an apparel library of pictures, a color printer and color scanner. We are studying this system as an example of an apparel CAD/CAM system to help us in developing an information model for data required in the apparel industry.

\section{Further Reading:}

Each program in the ModaCAD system includes a user's manual, available from ModaCAD, Inc.

\section{Developer:}

ModaCAD, Inc.

1954 Cotner Avenue

Los Angeles, CA 90025

(213) $312-6632$

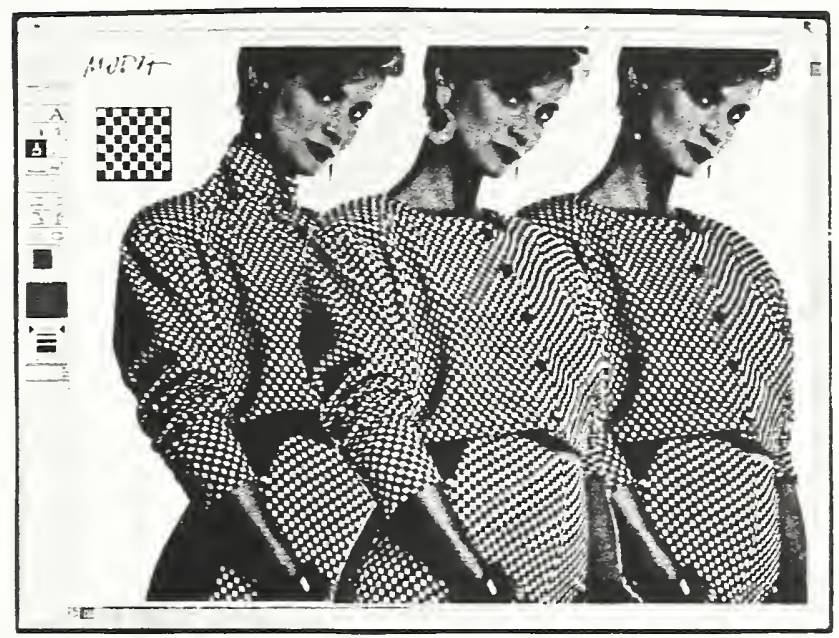

ModaCAD simulation of the finished garment on a live model. 



\section{Newton}

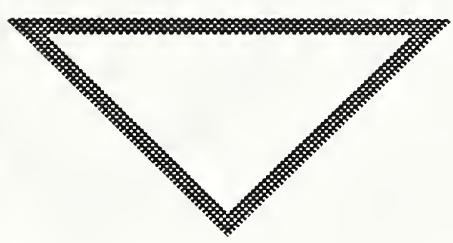

Newton is a research system developed at Cornell and Purdue Universities. Newton is a dynamic simulation system that simulates and analyzes systems of physical objects. The user specifies the shape, material composition, and the mechanical interrelationships of the objects. From this description the system constructs a variety of models, sometimes guided by additional user specifications, where each model captures the object behavior in a specific physical domain. Newton deals with the behavior of rigid bodies that can be hinged and interrelated in a number of ways. Given the description of shape and material composition, a set of motion equations is formulated automatically that expresses the dynamic behavior of the objects in Newtonian mechanics.

\section{Status:}

We will be using Newton to verify design criteria of the Molecular Modeling Machine project here at NIST. The current version of Newton has been installed and is running on the Sun 4 workstation. Newton requires Lucid Common Lisp and $\mathrm{X}$ Windows. CLX is needed if graphical output is desired. In addition, Newton runs on other engineering workstations including Silicon Graphics, Symbolics, and DEC.

\section{Further Reading:}

Cremer, Jim, An Architecture for General Purpose Physical System Simulation-Integrating Geometry, Dynamics and
Control, Cornell University, Ithaca, 1989.

\section{Developers:}

John Hopcroft

Department of Computer Science

4130B Upson Hall

Cornell University

Ithaca, New York 14853

(607) 255-7416

\section{Christoph Hoffman}

Department of Computer Science

Purdue University

West Lafayette, Indiana 47907

(317) $494-6010$

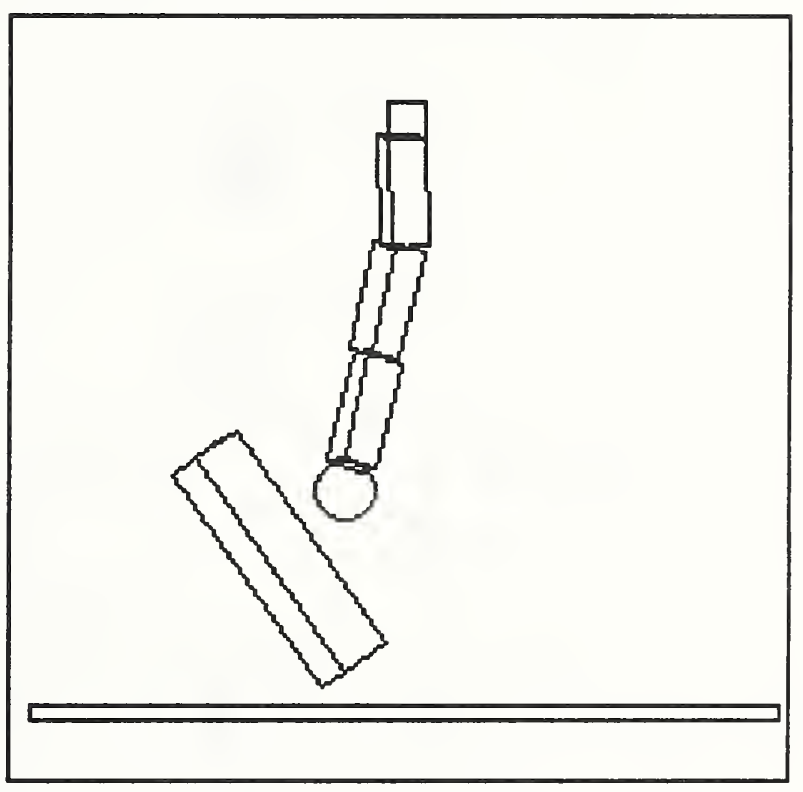

This is a Newton-generated image showing the physical reactions of a post and a multi-bar linkage assembly a few frames after the linkage has hit the post. 



\section{NextCut}

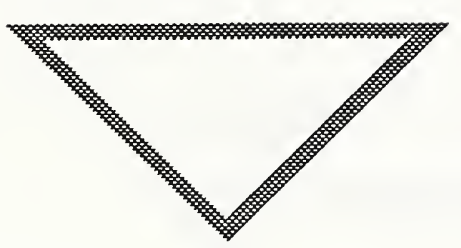

NextCut is a research CAD/CAM system from Stanford University. NextCut is built on the philosophy that the best way to assure Design for Manufacturability is to design products by specifying manufacturing plans for producing them. In NextCut the user simultaneously designs a product and the process used to manufacture it. Designers work in manufacturing modes (e.g., machining, molding, or assembly) adding features to a design or directly manipulating the process plan. An important aspect of manufacturing modes is that the user interface, and the features and operations that a designer works with, reflect the characteristics of the materials and processes under consideration. For example, machining mode supports material removal while assembly mode allows the designer to put things together. Manufacturing experts (or expert systems) check the resulting plans and fill in details after each step to ensure that no functional, geometric or manufacturing constraints are violated.

\section{Status:}

The current version of NextCut is installed on the Sun 4/330. NextCut runs on the Sun 4 workstation, and requires both Sun Common Lisp, Symbolic Programming Environment and Sunview for execution. NextCut is also available on the TI Explorer.

\section{Further Reading:}

Cutkosky, Mark R., Jay M. Tenenbaum, Dieter Muller, Features in ProcessBased Design, ASME CIE Conference, San Francisco, July 1988.

\section{Developers:}

Mark Cutkosky

Department of Mechanical Engineering

Stanford University

Stanford, California 94305

(415) 725-1588

Jay M. Tenenbaum

Center for Integrated Systems

Stanford University

Stanford, California 94305

(415) 725-3623

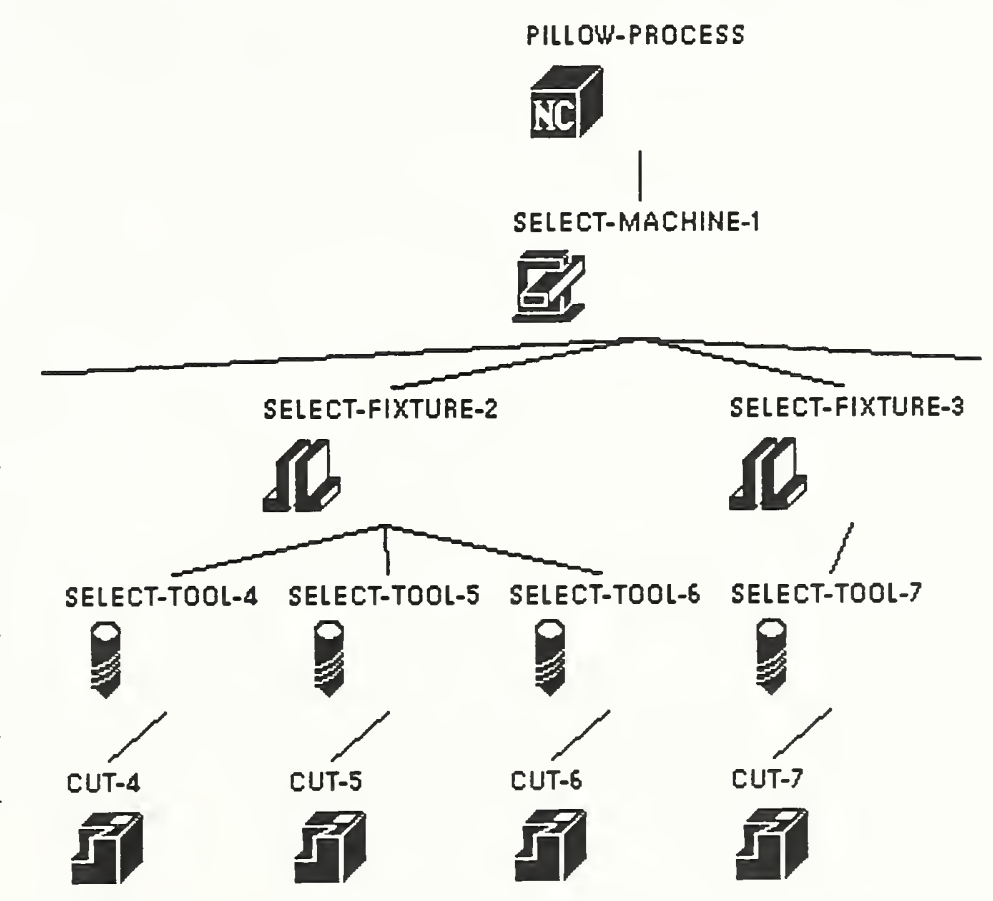

This illustration shows a portion of a process plan on NextCut. 



\section{N-See}

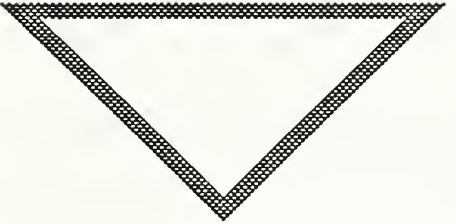

$\mathrm{N}-\mathrm{See}^{\mathrm{TM}}$ is a commercially available Numerical Control (NC) verification program. N-See allows you to see your workpiece as actually cut, both in-process and as a final part. N-See is based on a generalized octree solid model. The part is displayed in a realistic fashion and can be rotated, sectioned or zoomed at any time. Some of the capabilities supplied by N-See are simulation and verification of 2 and 3 axis milling operations, tool set up, and line by line execution of G-codes. All G-codes accepted by an ISO/FANUC/Japan Industrial Standard G-code are supported.

\section{Status:}

The current version 1.15 of $\mathrm{N}$-See is installed on the IBM PS/ 2 in the EDL. In general, N-See runs on a 286,386 or 486 based PC with an EGA or VGA graphics board, serial mouse, and math co-processor.

\section{Further Reading:}

N-See User's Manual, Microcompatibles, Inc., Silver Spring, 1989.

\section{Developer:}

\section{Donald M. Esterling}

Microcompatibles, Inc.

301 Prelude Drive

Silver Spring, Maryland 20901

(301) 593-0683 



\section{Parasolid}

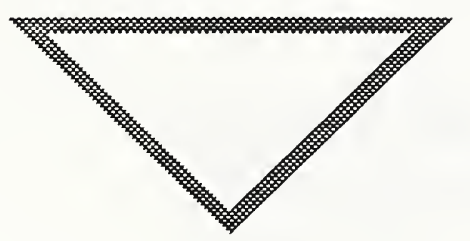

Parasolid is a commercially available kernel-based solid geometric modeling system. Parasolid library functions construct exact boundary representations with fully integrated parametric surfaces. One can build models with simple surfaces, rolling ball blends, and rational Bezier surfaces. Parasolid supports assemblies, various geometrical construction entities, and limited graphical output such as hidden lines and tessellation. In addition, user defined attributes can be attached to topological and geometric entities, and items in the database may be grouped together as features and manipulated by local operations. Bodies may be created by use of $3 \mathrm{D}$ primitives or by sweep operations on sheets or wires defined by bezier surfaces or curves. Bodies may be modified by solid set operations on sheets or solids, sectioning of bodies, sectioning with parametric surface sheets, and mirroring and repositioning of bodies. Local operations on bodies include: adding fillets and chamfers, rotation and linear translation of faces, copying or removing groups of faces to create a new body, moving or rotating groups of faces within the existing body, and representing rolling ball blends with special implicit blend surfaces.

\section{Status:}

We are using Parasolid with ICAD and in other functions within the EDL. Parasolid is also currently being used to support STEP efforts at NIST. We have version 2.2 running on the Sun 4 workstation. Additionally, Parasolid runs on a variety of engi- neering workstations (e.g. Apollo, DEC, $\mathrm{HP}$, and Sun).

\section{Further Reading:}

Overview of Parasolid, Shape Data Limited, Cambridge, England, 1988

Parasolid 2.0 Reference Manual, Shape Data Limited, Cambridge, England, 1989.

\section{Developer:}

Shape Data Limited

Parker's House

46 Regent Street

Cambridge CB2 1DB, England

(0223) 316673

For information within the US contact:

Ron Davidson

McDonnell Douglas Manufacturing and

Engineering Systems Company

$325 \mathrm{McD}$ onnell Boulevard

Hazelwood, Missouri 60342

(714) 952-6117

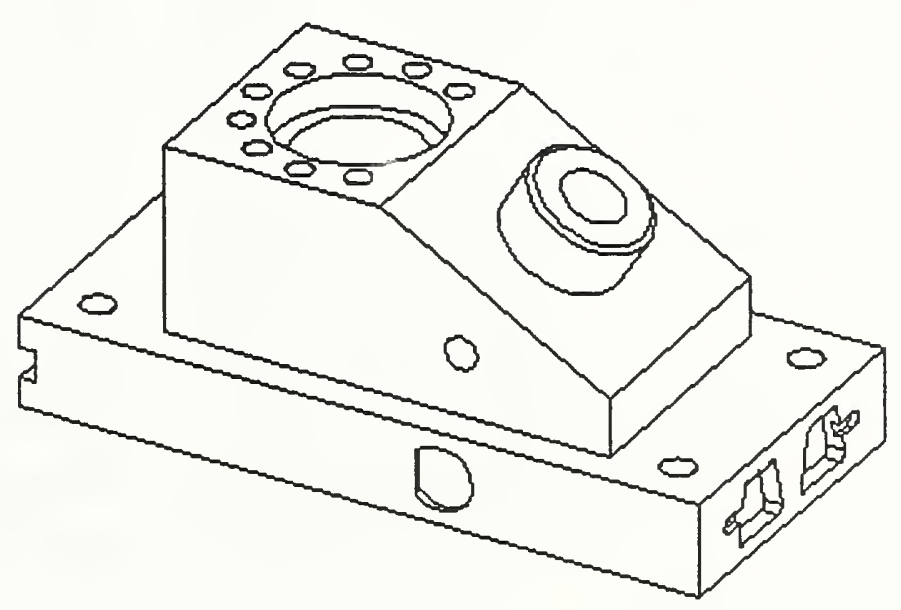

This hidden line image was generated in Parasolid. 



\section{Supporting \\ Hardware and \\ Software}

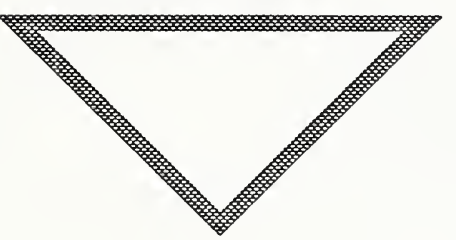

Sun Microsystems

The backbone of the EDL is a Sun 4/ 330 SPARC based server with 32 megabytes of physical memory, GX graphics accelerator board, color monitor, 2.3 gigabytes of hard disk storage and an $8 \mathrm{~mm}$ tape backup system. The software installed on this machine includes the Sun operating system, X Windows, Sun Common Lisp, Symbolic Programming Environment, Parasolid solid modeling system, Hoops graphics software, COSMOS/M finite element analysis software, ICAD design system, emacs, and Framemaker desktop publishing software.

Additionally, there are two SPARCstation 1 computers equipped with 16 megabytes of physical memory, local disks, color monitors, and graphics accelerators and two Sun $3 / 80$ workstations, each with 16 megabytes of memory and monochrome monitors.

\section{Silicon Graphics}

The EDL is home for a Silicon Graphics Iris 2400 Turbo. The Iris has 12 megabytes of memory, hardware floating point and hardware Z-buffer. Installed software on the Iris includes Common Lisp and Alpha_1.

\section{IBM}

An IBM PS/2 Model 70/A21, with an Intel 486 power platform, 8514 color monitor and graphics system, 8 megabytes of memory, 120 megabyte hard disk, ethernet card, DOS 3.31, and IBM AIX is an integral part of the design lab. Installed software packages include $\mathrm{N}$-See verification software, Turbo $\mathrm{C}$ and Turbo $\mathrm{C}++$ programming environments, Wordperfect 5.0, CADKEY CAD package, and COSMOS/ $M$ finite element analysis software.

\section{Apple}

Also in the EDL is an Apple Macintosh IIx, with 8 megabytes of physical memory, 160 megabyte internal hard disk, 24 bit color board, a WORM optical 5.25 inch drive, and two removable 45 megabyte drives. Additional hardware includes a Howtek Scanmaster color scanner and Tektronix 4693DX color printer. The Mac II runs TOPS, a C programming environment, and numerous paint and publishing packages.

\section{Communications}

All of the systems in the EDL are connected via Internet to the outside world and to other systems at NIST. 



\section{Facility}
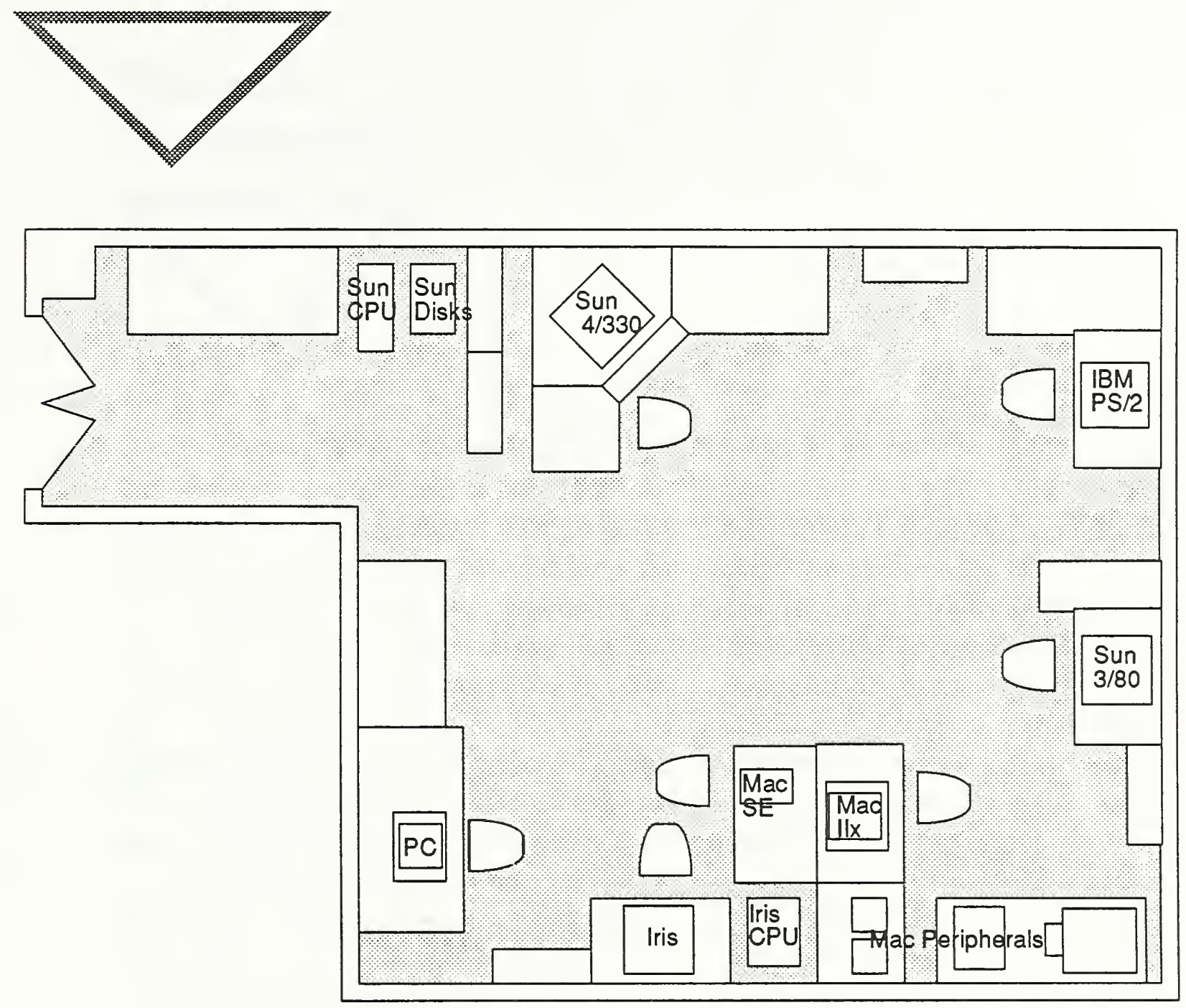

The Engineering Design Laboratory is located in Building 304, Room 5 at the National Institute of Standards and Technology in Gaithersburg, Maryland. The above diagram outlines current configuration of the physical facility. Any questions, comments or suggestions concerning the facilities or the design research conducted in the EDL are welcomed.

\section{Contact:}

Peter F. Brown, Project Manager Machine Intelligence Group Factory Automation Systems Division National Institute of Standards and Technology Metrology Building A127

Gaithersburg, Maryland 20899 (301) 975-3544 



\section{Research}

\section{Opportunities}

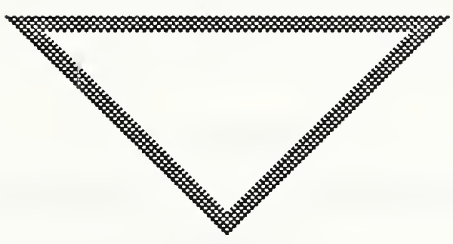

With the Omnibus Trade and competitiveness Act of 1988, NIST was designated the federal government's catalyst for speeding innovation and accelerating the adoption of new technologies and ideas by U.S. companies. This legislation opens up even more avenues for cooperation between NIST and universities, industry, federal laboratories, state and local governments--any organizations that have a stake in helping U.S. business compete more effectively in the world market.

One of the most popular ways NIST facilities are made available to industry is through the Research Associate Program. In this program, organizations sponsor research associates to work at NIST, providing salary, fringe benefits, and travel, while NIST provides use of the facilities, equipment and its broad base of expertise.

Another type of cooperative venture involves the donation (or loan) of software and/or hardware for use by NIST research- ers on projects that could ultimately improve a company's product or way they do business. In these cases, companies may advise NIST researchers on the needs and concerns of the industry.

The scope, duration, and structure of the research agreements are determined by the problem to be solved. These agreements can last from a few weeks to years and can involve one or many organizations. The goal at hand is to solve the problem effectively and efficiently.

\section{Contact:}

David E. Edgerly

Director, Office of Research and Technology Applications

Room A573, Building 301

National Institute of Standards and Technology

Gaithersburg, Maryland 20899 (301) 975-3087 



\begin{tabular}{|c|c|}
\hline \multirow[t]{4}{*}{$\begin{array}{r}\text { U.S. DEPARTMENT OF COMMERCE } \\
\text { NATIONAL INSTITUTE OF STANDARDS AND TECHNOLOGY }\end{array}$} & $\begin{array}{l}\text { 8. PUBLCATION OR REPORT NUMBER } \\
\text { NISTIR } 4519\end{array}$ \\
\hline & 2 PERFOAMING ORGAMIZATIOH REPOAT NUMBEA \\
\hline & \\
\hline & $\begin{array}{l}\text { 3. PUEUCATIONDATE } \\
\text { FEBRUARY } 1991\end{array}$ \\
\hline \multicolumn{2}{|l|}{ 4. TITLE AND SUBTITLE } \\
\hline \multicolumn{2}{|l|}{ Engineering Design Laboratory Guide } \\
\hline \multicolumn{2}{|l|}{ 5. AUTHOR(S) } \\
\hline \multicolumn{2}{|l|}{ Allison Barnard Feeney } \\
\hline \multirow{3}{*}{ 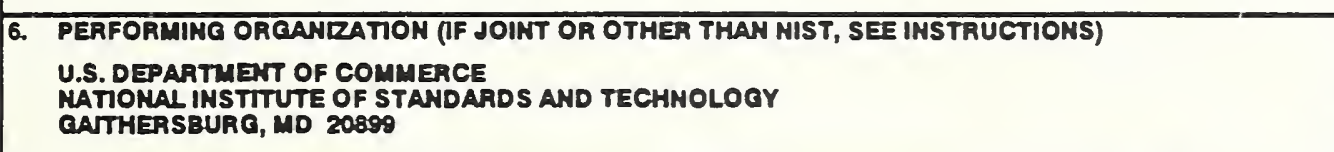 } & \multirow[t]{2}{*}{ 7. CONTRACT/GRANT NUMBER } \\
\hline & \\
\hline & 8. TYPE OF REPORT AND PERIOD COVERED \\
\hline
\end{tabular}

9. SPONSORIMG ORGANIZATION MAME AND COMPLETE ADDRESS (STREET, CTY, STATE, ZP)

10. SUPPLEMENTARY NOTES

11. ABSTRACT (A 200-WORD OR LESS FACTUAL SUMMARY OF MOST SIGMIFICANT INFORMATION. IF DOCUMENT INCWDES A SIGNIFICANT BIBUOGRAPHY OR UTERATURE SURVEY, MENTION IT HERE)

This document provides a brief description of the systems available for use in the Engineering Design Laboratory at the National Institute of Standards and Technology, Gaithersburg, Maryland. The Engineering Design Laboratory was established to study the process of design, how design information can be represented, and how to make design information available to necessary systems throughout a product's life cycle. This document also discusses opportunities for collaborative or independant research in the Enginetring Design Lab.

12. KEY WORDS (B TO 12 ENTRIES; ALPLABETCAL ORDER; CAPTTALEE OMLY PROPER MMES; AND SEPARATE KEY WORDS BY SEMICOLOHS)

ápparel design, design laboratory, finite element modeling, knowledge based software, solid modeling

FOR OFFICLL DISTRIEUTIOH. DO NOT RELASE TO MATONLL TECHMICN WFORMATION SERVCE (NTIS).

ORDER FROM SUPERINTENDERT OF DOCUMEMTS, U.S. COVERMMERT PRIMTHA OFFCE, WASHMATOH, DC 20402

14. MUMBER OF PAINTED PAQES

18

15. PAICE

$\mathrm{AO2}$ 




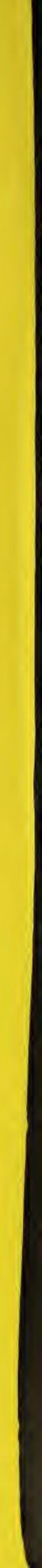

